\title{
Conceptual Design of a 1MW 175MHz CW Magnetron
}

\author{
Richard G Carter \\ Engineering Department \\ Lancaster University \\ Lancaster, LA1 4YR, UK
}

\begin{abstract}
Recent advances in the control of $\mathrm{CW}$ magnetrons have raised the possibility of using these devices as the RF power sources for particle accelerators. This paper describes the conceptual design of a $1 M W$, $175 \mathrm{MHz}, \mathrm{CW}$ magnetron and compares its performance with tetrode amplifiers.
\end{abstract}

Keywords: Magnetron; Conceptual design; Tetrode amplifier.

\section{Introduction}

Many proton accelerators require RF power sources capable of generating $1 \mathrm{MW} \mathrm{CW}$ at frequencies around $200 \mathrm{MHz}$. At present the only power sources available are tetrodes and similar gridded tubes operated as class B or C amplifiers with efficiency in the range $65-70 \%$ and gain in the range $10-15 \mathrm{~dB}$.

Recent advances in phase-locked CW magnetrons have shown that it is possible to achieve phase stability of better than $1^{\circ}$ with a locking power more than $30 \mathrm{~dB}$ below the output power of the tube [1]. This has raised the possibility of using CW magnetrons as RF power sources for particle accelerators. Figure 1 shows the state of the art of $\mathrm{CW}$ magnetrons including data from commercial data sheets and from an experimental tube [2]. Since efficiencies of up to $90 \%$ can be obtained at $915 \mathrm{MHz}$ it is reasonable to suppose that similar, or better, performance could be obtained at $200 \mathrm{MHz}$. The commercial tubes included in fig. 1 have $P f^{2}$ products of up to $84 \mathrm{~kW} . \mathrm{GHz}^{2}$ at $915 \mathrm{MHz}$ and $180 \mathrm{~kW} . \mathrm{GHz}^{2}$ at $2450 \mathrm{MHz}$. For $1 \mathrm{MW}$ at $200 \mathrm{MHz}$ the $P f^{2}$ product required is $40 \mathrm{~kW} . \mathrm{GHz}^{2}$ which is well within the limits of current technology.

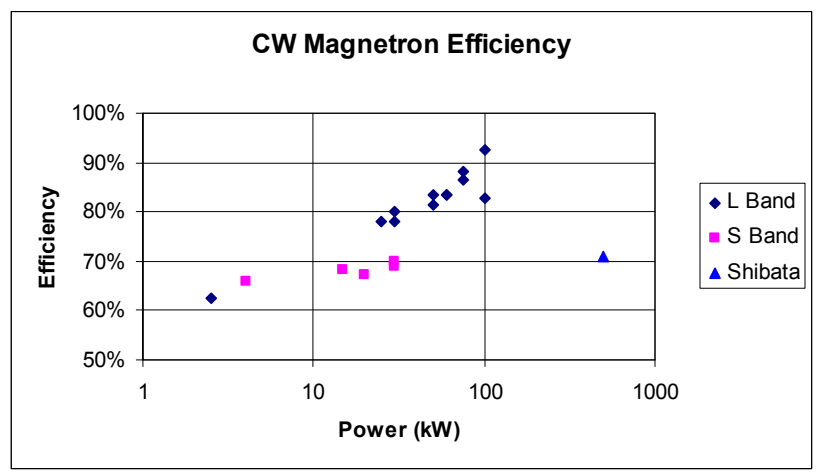

Figure 1. State of the art of CW magnetrons

This paper describes the conceptual design of a $1 \mathrm{MW}$, $175 \mathrm{MHz}, \mathrm{CW}$ magnetron for IFMIF as a possible alternative to the Thales TH628 Diacrode ${ }^{\circledR}$ which is the baseline design [3].

\section{Magnetron Design}

The conceptual design procedures for magnetrons are well understood and can be implemented using a spreadsheet. The calculations described in this paper were implemented on a MathCad worksheet which was been benchmarked against the design calculations in [2] and against other tubes.

Target efficiency: A target efficiency of $90 \%$ was assumed. The efficiency of a magnetron increases with the magnetic field approximately as shown in fig.2. It is clear from this graph that efficiencies greater than $90 \%$ can only be achieved by using very high magnetic fields which would require large electromagnets and large power supplies. The experimental tube described in [2] used a normalized magnetic field of 6.5 corresponding to a theoretical efficiency of around $80 \%$ and a practical efficiency of $72.5 \%$. However, since the actual field required is quite low at $175 \mathrm{MHz}$, a normalized magnetic field of 20.5 was chosen with a view to obtaining practical efficiency of $90 \%$.

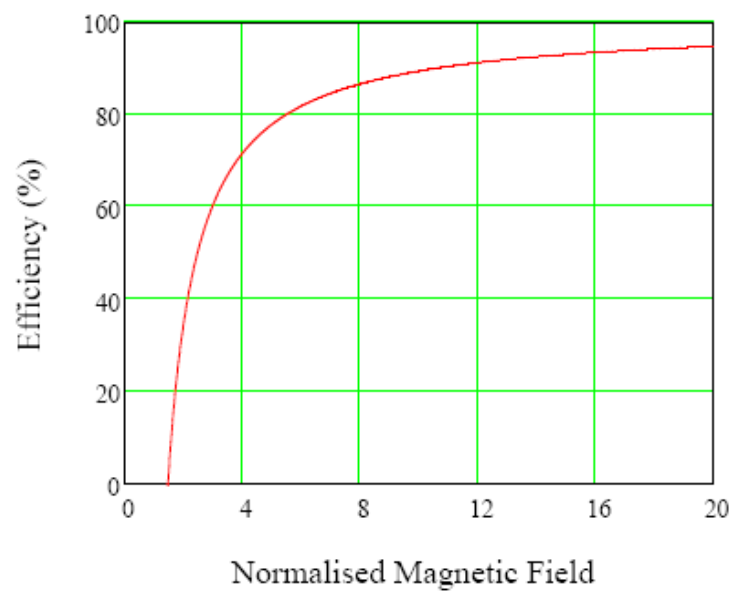

Figure 2. Variation of the efficiency of a magnetron with normalised magnetic field

DC Impedance: The impedances of $\mathrm{CW}$ magnetrons are typically in the range 3.0 to $7.0 \mathrm{k} \Omega$. The tube described in [2] had an impedance of $3.0 \mathrm{k} \Omega$. The phase locked loop which would be used to control the magnetron employs pulse width modulation of a switched mode power supply 
to control the current through the tube. It is desirable to keep the anode voltage as low as possible for compatibility with the high voltage switching devices currently available. An impedance of $3.0 \mathrm{k} \Omega$ therefore chosen.

Anode Design: The tube described in [2] had a coaxial cavity coupled to the anode vanes. However, the coaxial magnetron has the disadvantage that it is much larger than a conventional magnetron so that the size, weight, power requirements and self inductance of the electromagnet are increased. Other existing tubes at power levels which would scale to $1 \mathrm{MW}$ at $175 \mathrm{MHz}$ have conventional strapped anodes and that choice has been made in the design calculations. The choice of the number of vanes depends on a number of factors including: Cathode current density; Anode temperature; DC voltage breakdown and Stability. In general the first three criteria are easier to meet when the number of vanes is increased while the stability criterion (excitation of other modes of the anode) is harder to meet. The diameter of the anode increases with the number of vanes and so, therefore, does the size of the electromagnet. Calculations showed that cathode loading and voltage breakdown should not pose problems but that care would be needed with the thermal design of the anode. It was concluded that an anode with 10 vanes should be suitable.

Electromagnet: The magnetic field would be provided by a solenoid electromagnet surrounding the anode. The diameter of the anode controls the inside diameter of the windings and the height of the solenoid must be greater than that of the anode to provide for the anode end-space and cathode end hats. The current density in the windings was taken to be $1 \mathrm{~A} / \mathrm{mm}^{2}$. Previous experience suggests that this is a conservative choice and could be increased if necessary. It is desirable to minimize the self inductance and the working voltage in order to achieve the fastest possible rate of change of magnetic field as a way of controlling the output power. The results of these calculations are summarized in Table I.

Table I: Solenoid options

\begin{tabular}{|l|l|l|}
\hline Target efficiency & $90 \%$ & $85 \%$ \\
\hline Magnetic flux density & $885 \mathrm{G}$ & $435 \mathrm{G}$ \\
\hline Number of turns & 400 & 400 \\
\hline Solenoid current & $50 \mathrm{~A}$ & $24 \mathrm{~A}$ \\
\hline Solenoid voltage & $29 \mathrm{~V}$ & $14 \mathrm{~V}$ \\
\hline Solenoid power & $1.42 \mathrm{~kW}$ & $340 \mathrm{~W}$ \\
\hline Solenoid inductance & $0.94 \mathrm{H}$ & $0.94 \mathrm{H}$ \\
\hline $\begin{array}{l}\text { Voltage change to produce 1\% change } \\
\text { of output power in 100 msec }\end{array}$ & $94 \mathrm{~V}$ & $23 \mathrm{~V}$ \\
\hline
\end{tabular}

Stability: Magnetrons are liable to problems with the excitation of unwanted modes of the anode, especially the $\pi$ -1 and $\pi+1$ modes which are closest in frequency to the desired mode of operation. Careful design of the strapping of the anode can raise the frequencies of both these modes well above the frequency of operation so that no problems are envisaged with the number of anode vanes chosen. The operating point was chosen so that application of the correct working voltage should ensure that the desired mode of operation is selected preferentially. Stability of operation is further ensured by the phase locked loop. The output coupler could be designed to further increase the stability of the desired mode.

Cathode and tube life: High power $\mathrm{CW}$ magnetrons generally have directly heated thermionic cathodes made of tungsten wire. The current flowing in the wire produces a magnetic field which could disturb the operation of the magnetron. Possible alternatives might be an indirectly heated cathode or a 'cold' oxidized aluminium cathode (as in some crossed-field amplifiers). The back-bombardment of the cathode deposits between $2 \%$ and $5 \%$ of the input DC power on the cathode in the form of heat. It would therefore be necessary to provide cooling of the cathode [2]. Research would be needed to optimise the design of the tube to achieve long cathode life.

\section{Conclusion}

Table II shows the main operating parameters of the proposed magnetron with those of the TH628 Diacrode for comparison.

Table II

\begin{tabular}{|l|l|l|}
\hline & Diacrode & Magnetron \\
\hline Anode voltage & $14 \mathrm{kV}$ & $60 \mathrm{kV}$ \\
\hline Anode current & $103 \mathrm{~A}$ & $20 \mathrm{~A}$ \\
\hline Efficiency & $71 \%$ & $90 \%$ \\
\hline Gain & $13 \mathrm{~dB}$ & $>30 \mathrm{~dB}$ \\
\hline Drive power & $50 \mathrm{~kW}$ & $<1 \mathrm{~kW}$ \\
\hline Cooling & Anode & Anode and (probably) cathode \\
\hline Electromagnet & No & Yes \\
\hline
\end{tabular}

The study showed that it should be possible to develop a $1 \mathrm{MW}, 175 \mathrm{MHz}, \mathrm{CW}$ magnetron which would have appreciably higher efficiency and gain than an amplifier using a gridded tube. The power supply required is similar to those already in use for other purposes.

\section{References}

1. Tahir, I., Dexter, A. and Carter, R., "Use of DSP and Fast Feedback for Accurate Phase Control of an Injection Locked Magnetron", Proc. IVEC 2006, pp.559-560, Monterey, CA, April 25-27.

2. Shibata, C. et al., "High-power $(500 \mathrm{~kW}) \mathrm{CW}$ magnetron for microwave heating", Elect. Engg Japan, vol.111, no.2, pp.94-101, (1991).

3. IFMIF Comprehensive Design Report, 2003

4. Carter, R. and Beard,C., "Assessment of alternative RF power sources for IFMIF", EFDA Reference: TW6TTMI-001, The Cockcroft Institute, Sept. 2006 